\title{
O trágico Pacote do Veneno: lições para a sociedade e a Saúde Coletiva
}

\author{
The tragic "Poison Package": lessons for Brazilian \\ society and Public Health
}
El trágico "Paquete del Veneno": lecciones para la sociedad brasileña y la Salud Colectiva

Marcelo Firpo de Souza Porto 1

doi: 10.1590/0102-311X00110118

O Projeto de Lei (PL) no 6.299/2002 foi denominado de Pacote do Veneno pelo dossiê conjunto da Associação Brasileira de Saúde Coletiva (Abrasco) e da Associação Brasileira de Agroecologia (ABA) entregue no final de maio de 2018 ao Congresso Nacional. Ele é trágico e emblemático para analisarmos a atual conjuntura político-institucional do país a partir dos problemas socioecológicos e de saúde pública provocados pelo modelo de desenvolvimento agrícola. Desde o impeachment da Presidenta Dilma Rousseff o Governo Federal e o Congresso Nacional têm acelerado mudanças de políticas públicas e legislação que seguem a agenda do "mercado", essa estranha entidade da ideologia neoliberal que orienta a globalização econômica e defende investidores financeiros e poderosos grupos transnacionais.

Em essência, o PL 6.299 reuniu diversos outros PLs que se encontravam tramitando no Congresso Nacional desde 1999 até 2017. Ele assume a primazia dos interesses econômicos do agronegócio no lugar da defesa da saúde e do meio ambiente, a começar pela substituição do conceito de agrotóxico pelo de "produtos fitossanitários". Retira da Agência Naional de Vigilância Sanitária (Anvisa) e do Instituto Brasileiro do Meio Ambiente e dos Recursos Naturais Renováveis (Ibama) diversas atribuições no processo de licenciamento, ampliando os poderes regulatórios do Ministério da Agricultura. O PL 6.299 substitui a Lei no 7.802 de 1989, conhecida como a Lei do Agrotóxico, um importante marco no processo de redemocratização do país e na articulação política entre a saúde coletiva e o ambientalismo, com amplo apoio de sindicatos, movimentos sociais e setores da sociedade civil. O Pacote do Veneno desmonta esse amplo arcabouço legal e a estrutura institucional vigente no país, que só não avançou mais pela lacuna entre a legislação e a prática das instituições. Essa lacuna revela intensas contradições geradas pelas forças econômicas, políticas e midiáticas que sustentam o modelo do agronegócio.

O tema dos agrotóxicos ganhou destaque nacional desde 2008, quando foi divulgado que o Brasil havia se tornado o líder do ranking mundial de consumo. Em 2011 foi criada a Campanha Permanente contra os Agrotóxicos e pela Vida, que reuniu inúmeros movimentos sociais e sindicais, ONGs, universidades e instituições de pesquisa. No mesmo ano houve o lançamento do filme $O$ Veneno está na Mesa, do cineasta Silvio Tendler, e em 2015 foi publicado o livro Dossiê ABRASCO: Um Alerta Sobre os Impactos dos Agrotóxicos 1 . Além das denúncias, essas iniciativas apresentam como alternativa a viabilidade da agricultura familiar e agroecológica na produção de alimentos saudáveis e na construção de uma sociedade mais justa, democrática e sustentável.
${ }^{1}$ Escola Nacional de Saúde Pública Sergio Arouca, Fundação Oswaldo Cruz, Rio de Janeiro, Brasil.

\section{Correspondência} M. F. S. Porto Centro de Estudos da Saúde do Trabalhador e Ecologia Humana, Escola Nacional de Saúde Pública Sergio Arouca, Fundação Oswaldo Cruz. Rua Leopoldo Bulhões 1480, sala 302, Rio de Janeiro, RJ 21031-210, Brasil.

marcelo.firpo@ensp.fiocruz.br 
O reconhecimento de que saúde depende das relações sociais, ecológicas, culturais e espirituais para se realizar, seja como ciclo virtuoso ou trágico, inspirou a área de Saúde e Ambiente dentro da Abrasco 2 e propiciou a aproximação de grupos acadêmicos com as questões socioecológicas, os conflitos ambientais e os movimentos sociais nos últimos vinte anos. No caso do agronegócio e dos agrotóxicos, os coletivos e movimentos sociais que participam das resistências e alternativas são principalmente os camponeses, agricultores familiares, indígenas, quilombolas, extrativistas, pescadores artesanais, dentre outros, além do forte destaque do feminismo em sua luta contra o patriarcado. Nas cidades há também movimentos de consumo consciente, alimentação saudável, agricultura urbana e feiras agroecológicas.

Diversas iniciativas elevaram a consciência da sociedade sobre o problema, mas sempre tiveram que enfrentar o poderoso lobby do agronegócio e ações da bancada ruralista, que aproveitou a atual conjuntura política e governamental do país para aprovar o PL 6.229. Ele representa um enorme retrocesso, pois caminha na direção contrária à defesa dos direitos humanos, da saúde e da natureza. Tal posição reúne inúmeras entidades e instituições além da Abrasco e ABA, como a Sociedade Brasileira para o Progresso da Ciência (SBPC), a Fundação Oswaldo Cruz (Fiocruz), o Instituto Nacional de Câncer José Alencar Gomes da Silva (INCA), organizações ambientalistas e de defesa dos consumidores, até agências governamentais como a Anvisa e o Ibama. A própria consulta digital não vinculativa feita pela Câmara dos Deputados indicou cerca de 90\% de pessoas contrárias ao PL.

Mesmo com fortes pressões públicas contrárias, inclusive de inúmeras figuras públicas e artistas, em 25 de junho de 2018 a Comissão Especial deliberou em sessão tumultuada pela aprovação por ampla maioria do parecer do relator, o Deputado Luiz Nishimori (PR-PR). Com a aprovação o PL não precisará passar pelas comissões permanentes e poderá ser colocado rapidamente na Ordem do Dia da Casa para votação definitiva. Caso aprovado, a única esperança que restará à oposição e às entidades da sociedade civil contrárias ao Pacote do Veneno é a proposição de uma ação direta de inconstitucionalidade ao Supremo Tribunal Federal (STF).

Passados quase trinta anos da Lei dos Agrotóxicos, idade semelhante à da chamada Constituição Cidadã de 1988 e das Leis Orgânicas de Saúde aprovadas em 1990 que regulamentaram o Sistema Único de Saúde (SUS), vivemos um retrocesso civilizatório. Caminhamos na direção contrária a vários países do planeta com maior consciência ecológica e sanitária onde tem havido uma redução dos agrotóxicos no consumo global e por área plantada, com maior incentivo ao consumo de alimentos saudáveis, orgânicos e agroecológicos, sem com isso diminuir a produtividade e os ganhos econômicos na produção de diversas culturas.

Como o país passou a consumir tanto agrotóxico, e mesmo assim caminha para aprovar majoritariamente uma legislação tão retrógrada? Ao aprofundarmos a busca por respostas, creio que entramos no âmago das crises social, ecológica e de saúde que fazem parte de uma crise mais ampla, civilizatória.

No caso dos agrotóxicos, o elo com a crise mais ampla tem a ver com o modelo de desenvolvimento dos países neoextrativistas 3 do Sul Global exportadores de commodities agrícolas e metálicas. Como explica Guilherme Delgado 4, o apoio ao agronegócio (e também à mineração e siderurgia) foi fundamental para o saldo positivo da balança comercial desde a virada do século, em boa parte graças ao chamado "efeito China" que sustentou os preços das commodities. Com isso vários países latino-americanos reduziram suas dívidas externas e os mais progressistas ampliaram políticas sociais redistributivas. Segundo Delgado, embora conjunturalmente compensatória, a especialização primária das exportações é uma perigosa armadilha: não resolve a dependência externa e ainda agrava a situação deficitária de outros setores com potencial para serem mais justos e sustentáveis 4 .

No caso do agronegócio, monocultivos de exportação como a soja explicam a dependência química ${ }^{5}$, inevitável em sistemas ecológicos homogêneos que concentram a produção mundial de alimentos a poucas espécies vegetais e animais, com mercados longos que distanciam e alienam os consumidores. A agricultura industrial trava uma guerra contra a natureza e a biodiversidade vira uma praga a ser destruída. Não é casual que os primeiros agrotóxicos tenham origem na I Guerra Mundial, e posteriormente tais "inovações" transformaram-se num dos pilares da "Revolução Verde" que prometia acabar com a fome no mundo.

O conceito de Impérios Alimentares criada por van der Ploeg 6 é pedagógico para compreendermos a agricultura capitalista globalizada. Dela fazem parte os grandes donos de terra, mas também as empresas transnacionais que atuam no mercado global e constituem o regime alimentar global com 
forte poder monopólico na produção, processamento, distribuição e consumo de alimentos. Também incluem as indústrias de fertilizantes, agrotóxicos, transgênicos e outros insumos, além das grandes cadeias de supermercados. A destruição ambiental, as doenças e mortes provocadas por todas essas atividades econômicas são consideradas meros "efeitos colaterais", externalidades do mercado a serem eventualmente reduzidas. A questão, portanto, é bem mais ampla e complexa que uma bancada ruralista formada por atrasados "senhores da senzala".

Na virada do século XXI e com a chegada do PT à Presidência, criou-se um complexo e contraditório pacto político. A chamada bancada ruralista mais que dobrou entre a legislatura 1999-2002 para 2015-2018, e a balança comercial do agronegócio mais que quintuplicou. Tamanha poder busca se legitimar com campanhas publicitárias milionárias como "Agro é Pop, Agro é Tech, Agro é Tudo" criada pela Rede Globo.

Para comportar a política de alianças, garantir a governabilidade e dar continuidade ao superávit fiscal, o Presidente Luís Inácio Lula da Silva acomodou forças políticas antagônicas em dois ministérios: o todo poderoso Ministério da Agricultura, Pecuária e Abastecimento (MAPA), vinculado ao agronegócio; e o Ministério do Desenvolvimento Agrário (MDA), com um orçamento muito inferior. Apesar das contradições, desde 2003 as gestões do PT criaram ou ampliaram importantes políticas públicas de apoio à agricultura familiar, agroecologia e alimentação saudável, como o Programa Nacional de Fortalecimento da Agricultura Familiar, o Programa de Aquisição de Alimentos e o Programa Nacional de Alimentação Escolar. Mesmo com críticas, diversos movimentos sociais ligados à agricultura familiar e à reforma agrária apoiaram o MDA. Muitas entidades viram com esperanças o lançamento do Plano Nacional de Agroecologia e Produção Orgânica em 2012, porém ele nunca foi plenamente efetivado e jamais foi publicado o prometido Programa Nacional de Redução de Agrotóxicos.

Foi emblemática nos últimos anos do governo a relação da Presidenta Dilma Rousseff com a Senadora Katia Abreu (PDT-TO), liderança do agronegócio e fiel à Presidenta até sua saída. Podemos fazer uma analogia com um casamento no qual os cônjuges circulam por mundos paralelos. De um lado, respeita-se o esperado lado moral e institucional, no caso o crescimento econômico, ao lado do apaziguamento das tensões sociais pelo combate à fome e com políticas sociais distributivas, ainda que limitadas. Porém, simultaneamente convivem com o pior dos mundos onde reinam os violentos conflitos do campo, os assassinatos nas disputas por terra, o envenenamento da natureza, de trabalhadores e consumidores, os protestos de agricultores e movimentos sociais, o genocídio e o epistemicídio contra camponeses, povos indígenas e quilombolas.

Sob quais condições um casamento assim consegue perdurar, e até quando? Ou então, como um governo como o do PT conseguiu permanecer tanto tempo entre dois modelos de agricultura e de sociedade tão contraditórios dentro da "normalidade” institucional? Não é fácil responder questões tão complexas, o que pretendo trazer aqui são alguns elementos para ajudar a reflexão dos leitores.

Na perspectiva da Economia Política, a expansão da agricultura industrial capitalista, num contexto nacional ou regional, depende de como se produz acumulação, como as crises e conflitos são gerados e enfrentados, e as resistências e alternativas contra hegemônicas são construídas. A Ecologia Política 7 amplia o escopo da Economia Política por incorporar na análise as dimensões ecológica e territorial por meio do conceito de conflito ambiental. Nele o que está em disputa em setores como o agronegócio e a mineração são recursos como a terra, as águas, o controle territorial, as formas materiais e simbólicas de se produzir e viver, e tudo isso resulta no metabolismo social vigente. A questão de fundo de tais disputas envolve a defesa da vida e dos bens comuns versus o controle e a mercantilização da natureza e dos corpos. Esse é um nó central da crise democrática e do modelo de desenvolvimento na América Latina.

Existem pelo menos três opções estratégicas de expansão do agronegócio no contexto brasileiro. A primeira é a incorporação e subordinação dos agricultores familiares à cadeia do agronegócio, inclusive para enfraquecer a reforma agrária e movimentos sociais como o Movimento dos Trabalhadores Rurais Sem Terra (MST). Essa batalha foi permanentemente travada pelo agronegócio ao longo do governo do PT, porém com limites e resistências. A segunda estratégia é o aumento da área plantada através da retirada das terras indígenas, quilombolas ou daquelas protegidas pela legislação ambiental. Tal batalha foi e continua a ser travada pelos setores mais retrógrados e violentos do agronegócio, porém teve uma derrota recente no STF ao ser declarado constitucional o Decreto no 4.887/2003 
que regulamentou a oficialização dos quilombos. Infelizmente, tratou-se de uma vitória isolada em tempos difíceis para a democracia e os direitos humanos. O último relatório anual da Comissão Pastoral da Terra (CPT) lançado recentemente destaca o aumento da violência no campo e dos conflitos pela água 8 .

Uma terceira estratégia diz respeito ao aumento da produtividade da área plantada, e aqui entra o PL do veneno. O agronegócio afirma que os agroquímicos são fundamentais, porém, o que não é dito? Os monocultivos são dependentes químicos dos agrotóxicos, já que a agricultura industrial precisa eliminar a biodiversidade para plantar ou criar uma única espécie. Trata-se da ciência do controle para dominar, e não do convívio para o bem viver, princípio básico dos povos que vivem da e em harmonia com a natureza. Para eles a noção de bens comuns é componente integrante de suas cosmovisões, economias e saberes.

A dependência química do agronegócio gera um alto custo, não apenas pela compra de agrotóxicos e transgênicos. Afinal, quem paga pelas doenças e mortes da contaminação? Ou pela degradação ambiental e perda da biodiversidade? A triste resposta, expressa na valorizada linguagem dos números, encontra-se no que os economistas chamam de externalidades ambientais negativas, ou seja, os custos pagos pela sociedade como um todo e pelos grupos sociais mais atingidos, e não por aqueles que se beneficiam mais diretamente daquelas transações comerciais.

Estudo publicado em 20095 mostra que, no pior cenário, o custo associado à intoxicação aguda poderia representar até US\$ 149 milhões anuais apenas no Estado do Paraná. Para cada dólar gasto com a compra de agrotóxicos, até US\$1,28 seriam gastos com cuidados médicos decorrentes de intoxicação e com afastamentos do trabalho. E isso não inclui os custos bem maiores associados às doenças crônicas como o câncer, ou ainda os custos decorrentes da degradação ambiental. Outro estudo 9 analisou o uso de agrotóxicos no Brasil como exemplo de "paraíso da poluição". Por exemplo, caso o Brasil gastasse proporcionalmente o mesmo que os Estados Unidos com o controle e a fiscalização de agrotóxicos, o valor estimado seria de $\mathrm{R} \$ 14$ bilhões ou 5,8\% do PIB agropecuário, um valor muito maior do que é gasto atualmente. Além disso, os subsídios fornecidos aos agrotóxicos, considerados absurdamente "insumos agrícolas" da mesma maneira que tratores, indicam uma renúncia fiscal de quase um bilhão de dólares com base no Censo Agropecuário de 2006. Ou seja, boa parte da pujança econômica do agronegócio se realiza por não considerar a destruição de vidas e da natureza. Na década de 1970 a ditadura militar transformou o Brasil no campeão mundial dos acidentes de trabalho, e agora a PL 6.299 reforça o país como "paraíso da poluição".

O Pacote do Veneno e os atuais retrocessos das políticas de saúde, de proteção ambiental e das terras indígenas e quilombolas revelam o comportamento subalternizado e colonial de parcela relevante do agronegócio brasileiro e outros setores conservadores da sociedade. Ele tem a ver com o fim da aliança com o PT e o apoio ao golpe político-jurídico-midiático em curso, o qual possui uma geopolítica mais complexa. Não se trata de ser contra a agricultura brasileira, mas sim de considerar que o desenvolvimento econômico e social deve caminhar com respeito à vida, à saúde humana e ao meio ambiente, bem como aos direitos de indígenas, quilombolas e camponeses.

No fundo, o que está em jogo é uma batalha mais ampla sobre como produzir desenvolvimento econômico, científico e tecnológico com mais ética, respeito e solidariedade. Para pensadores como Boaventura de Sousa Santos 10, a ideologia neoliberal e a mercantilização da vida intensifica o projeto moderno eurocêntrico em seu lado mais desumano e explorador ao fundir o capitalismo e o colonialismo como eixos ontológicos e políticos que criam as condições para a liberação irrestrita dos fluxos financeiros. Isso vem permitindo que a natureza e os seres humanos se tornem coisas, e as coisas em sujeitos animados. Dessa forma as mercadorias, o dinheiro e o capital transformam-se em sujeitos sociais que decidem sobre a vida e a morte de todos os seres humanos, do planeta e de projetos de futuro 11, com expansão das distopias e restrições aos sonhos utópicos. Sem refletir sobre tais questões, continuaremos a reeditar os dilemas da era PT, mesmo em nome do pensamento crítico, inclusive frente às futuras eleições.

A Saúde Coletiva precisa se reinventar para enfrentar tamanhos desafios. Usando a metáfora do casamento, precisamos discutir nossas relações: com quem, como e para que nos relacionamos, seja com referenciais teóricos, metodologias, o Estado ou a sociedade? Para que servem nossas pesquisas e como nos envolvemos - ou não - nas lutas sociais mais relevantes? Até que ponto os venenos e os conflitos de interesse estão a corroer nossos princípios e práticas, até porque muitas vezes não são 
explicitados por exigências pragmáticas de coalizões políticas e financiamento de instituições, grupos acadêmicos e ONGs? Responder tais questões é uma tarefa premente das forças progressistas e dos intelectuais que buscam corazonar 12, um pensar-sentir mais ético e integrado de origem andina que concorre com as visões rasteiras e produtivistas que predominam na academia, inclusive dentro da própria Saúde Coletiva.

1. Carneiro FF, Rigotto RM, Augusto LGS, Friedrich K, Búrigo AC. Dossiê ABRASCO: um alerta sobre os impactos dos agrotóxicos na saúde. Rio de Janeiro: Escola Politécnica de Saúde Joaquim Venâncio, Fundação Oswaldo Cruz/São Paulo: Expressão Popular; 2015.

2. Augusto LGS, Tambellini AT, Miranda AC, Carneiro FF, Castro H, Porto MFS, et al. Desafios para a construção da "Saúde e Ambiente" na perspectiva do seu Grupo Temático da Associação Brasileira de Saúde Coletiva. Ciênc Saúde Coletiva 2014; 19:4081-9.

3. Gudynas E. Estado compensador y nuevos extractivismos: las ambivalencias del progresismo sudamericano. Nueva Sociedad 2012; 237:128-46.

4. Delgado GC. Especialização primária como limite ao desenvolvimento. Revista Desenvolvimento em Debate 2010; 2:111-25.

5. Soares WL, Porto MF. Estimating the social cost of pesticide use: an assessment from acute poisoning in Brazil. Ecol Econ 2009; 68:2721-8.

6. van der Ploeg JD. Camponeses e impérios alimentares: lutas por autonomia e sustentabilidade na era da globalização. Porto Alegre: Editora da UFRGS; 2008.

7. Porto MF, Martinez-Alier J. Ecologia política, economia ecológica e saúde coletiva: interfaces para a sustentabilidade do desenvolvimento e para a promoção da saúde. Cad Saúde Pública 2007; 23 Suppl 4:S503-2.
8. Passos C. Lançamento do relatório anual da CPT destaca o aumento da violência no campo e dos conflitos pela água. https://www. cptnacional.org.br/publicacoes/noticias/con flitos-no-campo/4380-lancamento-do-rela torio-anual-da-cpt-destaca-o-aumento-daviolencia-no-campo-e-dos-conflitos-pelaagua (acessado em 05/Jun/2018).

9. Brito LH. O consumo brasileiro de agrotóxicos sob análise da curva ambiental de Kuznets [Monografia de Graduação]. Rio de Janeiro: Escola Nacional de Ciências Estatísticas; 2016.

10. Santos BS. Para além do pensamento abissal: das linhas globais a uma ecologia de saberes. Revista Crítica de Ciências Sociais 2007; 78:3-46.

11. Hinkelammert FJ, Jimenez HM. Hacia una economía para la vida. 2a Ed. San José: Editorial Tecnológica de Costa Rica; 2005.

12. Guerrero Arias P. Corazonar el sentido de las epistemologías dominantes desde las sabidurías insurgentes, para construir sentidos otros de la existencia. Calle 14: Revista de Investigación en el Campo del Arte 2010; 4:80-95.

Recebido em 08/Jun/2017

Versão final reapresentada em 02/Jul/2018

Aprovado em 03/Jul/2018 